\title{
The effect of the length of list on characteristics of the serial position curve
}

DONALD R. YELEN, Washbum University, Topeka, Kans. 66621

Groups of 42 Ss learned serial lists of $8,11,14,17$, and 20 items. Linear functions were fitted to the five serial-position curves and were used to show that the relative speed of learning items at both ends of the lists was not affected by the length of the list, and that the relative position of the point of maximum difficulty decreases as a function of the length of the list.

The present study was conducted in order to determine the effects of the length of serial lists on the relative speed of learning the items at both ends of the list, and on the relative position of the point of maximum difficulty in the lists.

\section{METHOD}

Five list-length conditions were used: $8,11,14,17$, and 20 items. Six different serial lists for each length condition were constructed by using two samples of items and by arranging the items selected from each sample in three different orders. Each sample of items consisted of $20 \mathrm{CVCs}$ with either $47 \%$ or $53 \%$ association values (Glaze, 1928). No two CVCs in each sample started nor ended with the same consonant.

Forty-two experimentally naive students were assigned to each of the five list-length conditions. Seven students, four males and three females, learned one of the six lists from each length condition.

Instructions for serial learning by the anticipation method were given to the Ss. Training was then started and continued until the Ss reached a criterion of one errorless trial. The items were presented with a Stowe memory drum at a 2 -sec rate. A 6-sec intertrial interval was used.

\section{RESULTS AND DISCUSSION}

Figure 1 shows the serial position curves for the five list-length conditions. Each curve was constructed by ranking the mean number of errors made at each position. Fig. 1 also shows that the same linear function has been fitted to the positive, or increasing segments of each of the curves, and that lines with the same slope constants but with different intercept constants have been fitted to the negative, or decreasing, segments of the curves. Inspection indicates a reasonable fit between the linear functions and the observed ranks along both the positive and negative segments of the curves. The correlations (Pearson $r$ ) between the ranks of the mean number of errors at each of the serial positions and the ranks that were predicted by the fitted lines for the same positions were $.97, .98, .98, .93$, and .96 for the $8-, 11-, 14$, $17-$, and 20-item conditions, respectively. The proportion of variance in the observed ranks of the mean number of errors that can be attributed to the ranks predicted by the fitted lines ranges from .86 to .96 , and thus provides support for the observation that the lines fit both the positive and the negative segments of the curves.

The fact that the same line was fitted to the positive segments of each of the five serial-position curves indicates that the relative speed of learning the items at the beginning of a list is the same for all list-length conditions. In a similar manner, the fact that lines with the same slope were fitted to the negative segments of each of the five serial position curves indicates that the relative speed of learning the items at the end of a list is the same for all list-length conditions used in this study.

Figure 1 also shows that the line fitted to the positive segments of the curves is flatter than the lines fitted to the negative segments of the curves. This difference in slope indicates that the rate of learning items at the beginning of a

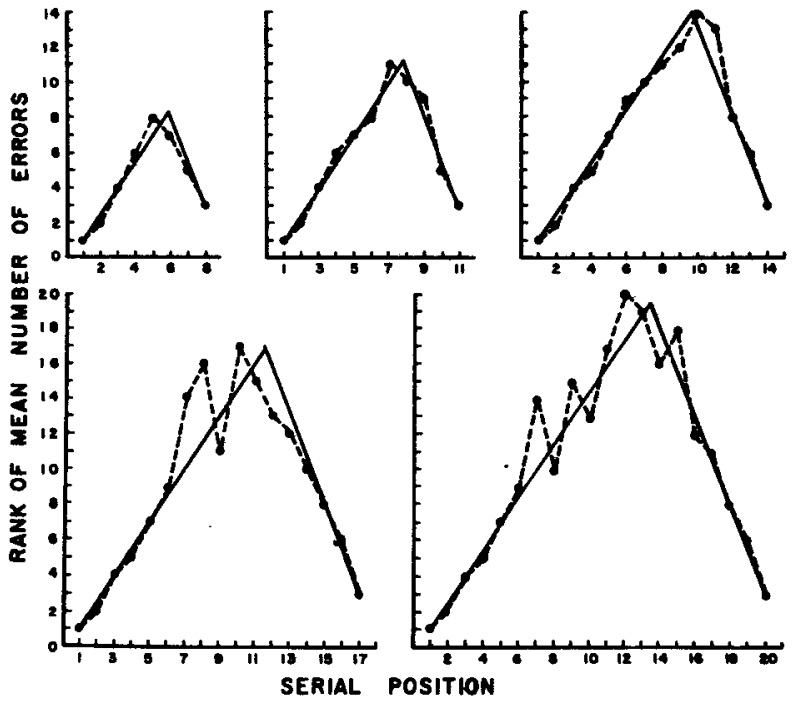

Fig. 1. Rank of the mean number of errors as a function of serial position for the 8-, 11-, 14-, 17-, and 20-item conditions.

list is faster than the rate of learning the items at the end of a list. This finding agrees with the previous observation (Ribback \& Underwood, 1950) that Ss learn serial lists from the ends towards the middle and that learning from the beginning is faster than learning from the end. The difference in slope shown in Fig. 1, however, conflicts with the order of serial learning proposed by Jensen (1962), since this order, at least when the first item is omitted, indicates that the rate of learning the items at the beginning of a list is exactly the same as the rate of learning the items at the end of a list.

The point of maximum difficulty for each of the five serial-position curves was estimated by using the intersection of the functions fitted to the positive and negative segments of the curves. The estimated points of maximum difficulty were $5.87,7.75,9.62,11.50$, and 13.37 for the $8-, 11-, 14-, 17$, and 20 -item conditions, respectively. It can be seen that the absolute position of these points increases as a function of the length of list, but that the relative position (e.g., the per cent the point of maximum difficulty is of the list length) decreases as a function of the length of list. Although this decrease is small, from $73 \%$ in the 8 -item condition to $67 \%$ in the 20 -item condition, it is in line with the data presented by Hovland (1940) and agrees with the position taken by McGeoch \& Irion (1952) that "as length of list increases, the relative distance from the beginning (or center) of the list to the point of maximum difficulty decreases [p. 123]," but conflicts with the position taken by Deese (1958) that "As more items are added, the point of maximum errors always remains in the same relative position [p. 172]."

\section{REFERENCES}

DEESE, J. The psychology of learning. New York: McGraw-Hill, 1958. GLAZE, J. A. The association value of nonsense syllables. Journal of Genetic Psy chology, 1928, 35, 255-269.

HOVLAND, C. I. Experimental studies in rote-learning theory. VII. Distribution of practice with varying lengths of list. Journal of Experimental Psychology, 1940, 27, 271-284.

JENSEN, A. R. An empirical theory of the serial-position effect. Jou mal of Psychology, 1962, 53, 127-142.

McGEOCH, J. A., \& IRION, A. L. The psychology of human learning. New York: Longmans, Green \& Co., 1952.

RIBBACK, A., \& UNDERWOOD, B. J. An empirical explanation of the bowed serial position curve. Journal of Experimental Psychology, $1950,40,329-335$. 